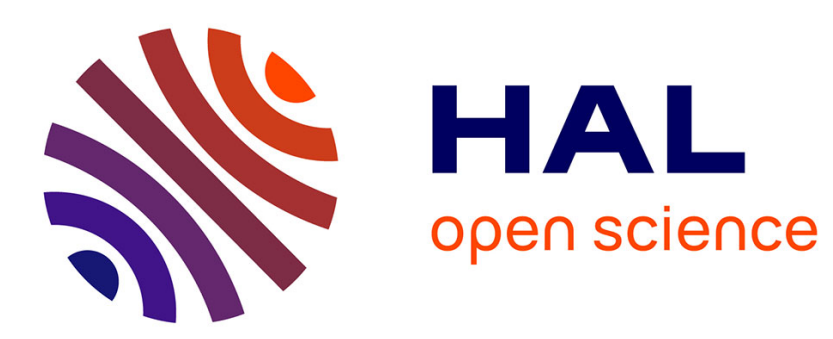

\title{
An Integrated Tool for the Optimization and Simulation of Hybrid Product-Process Layouts
}

\author{
Gianluca D'antonio, Paolo Chiabert
}

\section{To cite this version:}

Gianluca D'antonio, Paolo Chiabert. An Integrated Tool for the Optimization and Simulation of Hybrid Product-Process Layouts. 15th IFIP International Conference on Product Lifecycle Management (PLM), Jul 2018, Turin, Italy. pp.768-777, 10.1007/978-3-030-01614-2_70 . hal-02075593

\section{HAL Id: hal-02075593 \\ https://hal.inria.fr/hal-02075593}

Submitted on 21 Mar 2019

HAL is a multi-disciplinary open access archive for the deposit and dissemination of scientific research documents, whether they are published or not. The documents may come from teaching and research institutions in France or abroad, or from public or private research centers.
L'archive ouverte pluridisciplinaire HAL, est destinée au dépôt et à la diffusion de documents scientifiques de niveau recherche, publiés ou non, émanant des établissements d'enseignement et de recherche français ou étrangers, des laboratoires publics ou privés. 


\title{
An integrated tool for the optimization and simulation of hybrid product-process layouts
}

\author{
Gianluca D’Antonio, Paolo Chiabert \\ Politecnico di Torino, corso Duca degli Abruzzi 24, 10129 Turin, Italy \\ \{gianluca.dantonio, paolo.chiabert\}@polito.it
}

\begin{abstract}
The design of a manufacturing process is a crucial phase for ensuring a profitable production. In particular, an appropriate layout for the facilities must be identified to minimize the impact of transporting manufacturing units throughout the shop-floor on both process performance and production cost. In a former work, a mathematical model capable to define process, product and hybrid layouts has been defined by minimizing the average distance travelled by each manufacturing unit. The present paper aims to present an integrated tool able to: (i) deploy the optimization model to autonomously evaluate the optimal layout proposal that fits with a set of input provided by the designer; (ii) evaluate a set of KPIs to assess the layout; (iii) compile a discrete event simulation model on FlexSim to enable the designer to evaluate layout performance in a multiplicity of operating scenarios.
\end{abstract}

Keywords: Facility layout problem, Facilities planning and design, Optimal facility layout, Hybrid facility, Discrete event simulation

\section{Introduction}

The operating cost of a manufacturing process as well as its overall productivity is significantly affected by the position of the facilities within the shop-floor [1]. Tompkins et al. [2] found that $20-50 \%$ of the manufacturing costs are due to the handling of parts: a poor layout and flow design results in excessive work-in-process, high lead times, low or unbalanced equipment utilization and high costs for material handling and logistics equipment [3]. In other words, a weak arrangement of resources is a main source of wastes, according to the lean manufacturing classification.

The optimization of the facilities position is known as the Facility Layout Problem (FLP) and has been studied since the 1960s [4]: the problem aims to make layouts more efficient by considering various interactions between facilities and material-handling systems while designing layouts [5]. Nonetheless, FLP solution generally exhibits a NP-hard complexity [6] and is thus decomposed in simpler problems [7]. Various efforts have been made to systematize the knowledge about this class of problems: literature surveys have been proposed by Kusiak and Heragu [8], Meller and Gau [9], Singh and Sharma [10], Drira et al. [1], Anjos and Vieira [6]. Drira et al. [1] defined a classification for the organization of manufacturing systems that is now well-acknowledged:

adfa, p. 1, 2011.

(C) Springer-Verlag Berlin Heidelberg 2011 
- Fixed product layouts: the facilities circulate around the product (which is not moved) to perform the necessary operations;

- Process layouts: the facilities with similar functions are grouped together in cells, enabling to deal with a large variety of products;

- Product layouts: the facilities are organized to match with the sequence of manufacturing operations to be performed for obtaining a specific product;

- Cellular layout: heterogeneous resources are grouped into cells, and each cell is in charge of manufacturing a particular product family.

To choose the appropriate manufacturing layout for a given process, both the variety of involved products and the material handling system (MHS) must be considered. Most of the approaches available in literature take into account the rigidities due to the MHS. Nonetheless, the significant technical efforts spent in the last decades led to the availability of Automated Guided Vehicles (AGVs) capable to freely navigate into a given space and safely interact with other vehicles and with humans. This capability opens unprecedented possibilities for the FLP. Further, manufacturers increasingly require facilities capable to quickly shift from one product to another without huge investments for major retooling, resource reconfiguration, or replacement of equipment [11].

This paper aims to present a novel tool capable to define and simulate a layout proposal based on a hybrid product-process layout. The term hybrid is used because the tool is able to formulate product layouts, process layouts, and intermediate solutions in which process cells - with a proper number of machines - may be conveniently duplicated. The remainder of the paper is organized as follows. In Section 2 the existing methodologies to deal with the FLP are reviewed. The integrated tool for layout optimization and discrete event simulation (DES) is described in Section 3 and the results of some case-studies are presented in Section 4. Conclusive remarks and improvement perspectives are presented in Section 5.

\section{State of the art}

The unequal areas FLP (UA-FLP) has been first stated in 1963 by Armour and Buffa [4]. In literature, this problem is mainly dealt with a two-steps approach: (i) a given (rectangular) area is divided into a finite number of regions, each of them representing a different department, and a method to minimize the overall distance travelled by each manufacturing unit is used; (ii) the internal layout of each cell is then defined $[6,10]$. Usually, the facilities can be placed anywhere within the planar domain, provided that they must not overlap with each other [1].

Different methods have been proposed. First, researchers tried to solve exactly the FLP. A branch and bound approach was used by Kouvelis and Kim [13] to solve the unidirectional loop layout problem, while Xie and Sahinidis [14] solved a minimum-cost network flow problem to obtain a feasible layout from the sequence-pair representation of the relative position layout. However, obtaining a reliable solution requires too much time for dealing with huge problems and alternative heuristics have been developed. In 1991, Montreuil [15] began to use the Mixed-Integer Linear Programming (MILP): rectangular departments are arranged orthogonally in a rectangular facility, using 
binary variables to specify the relative location of each department pair and prevent their overlapping, on both the horizontal and the vertical directions. However, even problems with 5 or 6 departments exhibited big challenges. Thus, Meller et al. [16] redefined the binary variables in the MILP model and studied the structure of acyclic subgraphs. Sherali et al. [17] improved this formulation and solved a problem with 9 departments in less than 10 hours. Bukchin and Tzur [18] further improved the performance: they solved many problems made of 10 departments in less than 6 hours. Their algorithm was also able to simultaneously define the layout of the departments and their internal layout, including both departments rectangular and L/T department shapes.

An approach alternative to MILP consists in genetic algorithms (GA), which systematically search for a solution but do not guarantee optimality. Mak et al. [19] used GAs to minimize the cost of material handling cost in case all the departments have equal areas. Azadivar and Wang [20] developed an approach that integrates GAs and simulation, to both optimize the layout and evaluate its performance; they aimed to minimize the cycle time and maximize productivity. Nonetheless, GAs exhibit a non-linear computational cost, which is an issue for big FLPs. Thus, Dunker et al. [21] developed a coevolutionary algorithm: the huge problem is split into smaller ones linked with each other. Galaxe Paes et al. [22] used a strategy for problem decomposition and reconstruction to handle problems with big dimensions: they have been able to solve layouts with 150 facilities in a few minutes.

Other metaheuristics inspired to natural phenomena have also been developed. Komarudin [23] used an ant system, a discrete optimization technique that resembles the behaviour of an ant colony in finding the shortest path to reach its food source. Niroomand et al. [24] used the migrating birds optimization method. An approach based on collision detection and force exertion heuristics has been presented by Sikaroudi and Shahanaghi [25]. Each department is modeled as a centroid and a surrounding area: the centroids interact with each other through forces that avoid cells overlapping. Departments are placed randomly to set an initial solution; then, the algorithm iteratively converges towards the optimal solution. The authors were able to solve a layout made of 100 departments in 230-250 seconds.

In former work [26] a mathematical model to define hybrid product-process layouts has been presented. In the present work, we aim to introduce an integrated tool for exploiting this model and automatically compile a DES model to evaluate the performance of such layout in a multiplicity of operative scenarios.

\section{The optimization and simulation tool}

\subsection{Layout optimization}

The tool for layout optimization acquires in input a set of parameters provided by the user and a table containing the bill of process (BoP). Then, the following tasks are performed:

1. Definition of the process cells. This task aims to find a suitable grouping of the machines into cells to guarantee the fulfillment of the BoP. In order to implement 
the hybrid product-process approach, a parameter named Closeness is introduced. It represents the maximum, normalized distance in the BoP between two operations for which grouping in the same cell is admissible. So, the tool scans the BoP and for each operation reads the next Closeness percent of the list, searching for possible operations to be grouped with the one at stake. The value of Closeness is set by the user; in particular, setting this parameter to 0 or to 1 result in product or process layout, respectively; intermediate values lead to hybrid solutions and, hence, different cells performing operations technologically similar can be defined. This step leads to the creation of $C$ cells. Then, the duration of each operation (taken from the $\mathrm{BoP}$ ) and the desired takt time for the line (provided by the user) are considered to evaluate the number of machines necessary to keep stable each cell, i.e. to have an average utilization lower than 1 .

2. Definition of the layout within the cells. As a second step, the tool assigns the position of the machines within the above-defined cells. Each cell is made of identical machines, and no internal flow of manufacturing units (MUs) has to be considered. Therefore, a finite set of standardized cells designs can be defined a priori. At this stage, for each cell defined in the first step, the design corresponding to the number of machines to be contained is selected. This solution enables to solve the intra-cellular layout in a short time keeping a high quality of the design.

3. Definition of the cells position within the available area. In this task, the position of the cells is defined with the aim of minimizing the average distance travelled by each manufactured unit (MU). This is the trickiest task and relies on a mathematical algorithm that models the manufacturing process as a mechanical system of bodies connected with each other through a set of springs. The connected bodies represent the $C$ cells defined in the previous step, and the points where they enter and leave the process (for example, the warehouses for raw materials and finished products). The springs model the inter-cellular travels to be performed according to the BoP. The aim of the algorithm is to identify an equilibrium condition for the bodies, which corresponds to the minimum residual energy, that in turn provides the optimal position for the manufacturing cells. The complete description of the mathematical model can be found in [26].

4. Evaluation of KPIs for layout assessment. To objectively evaluate the layout proposal, a set of performance indicators is evaluated, including the number of machines and cells necessary to perform the process, an estimation of the area occupied by the machines, the overall average distance travelled by each MU. Also, the number of intersections among paths connecting different cells is evaluated: the higher is this number, the higher is the probability of traffic jams that may lower the performance of the line.

The tool has been implemented in Matlab, version R2017a. A graphical interface has been implemented to enable the user to quickly input data and consult the performance indicator; it is shown in Fig. 1, left panel. A snapshot of the layout is also generated. The data necessary for compiling the DES model are stored into an Excel spreadsheet, readable by both the simulation software and by the user. 


\subsection{Discrete event simulation}

In order to compile the simulation model, several objects have to be considered for each machine included in the layout proposal: (i) a processor, modeling the machine; (ii) a queue and a bay, to model the interface between the machine and the material handling system; (iii) a container for the components to be added to the product. Therefore, given $M$ machines to be included in the model, $O\left(M^{4}\right)$ objects are to be added, connected and customized in the model. Then, all the criteria to manage the flow of manufacturing units and the fleet of AGVs must be implemented. As the number of objects to be added in the model increases, this preparatory activity may become time consuming and error prone, although the added value provided to the designer is quite low.

Therefore, a higher-level approach has been undertaken. A meta-model containing the rules for providing the DES model with the objects and the flow rules has been developed. In this way, the model user just has to insert a few input; the model is ready for simulation or for fine tuning within a few seconds. In particular, the meta-model is able to:

1. Insert the entrance and exit points according to the coordinates input by the user;

2. Insert processors, queues, bays, components containers in the positions provided by the optimization model;

3. Insert the fleet of AGVs in charge of transporting both the MUs with the proper features for speed and acceleration;

4. Connect all of these objects in agreement with the BoP;

5. Set the rules for determining the setup and processing times, and the destination of the MU: each processor may load MUs at different stages of development, with different processing duration and different destinations.

The model can also take into account the consumption of components necessary for the manufacturing process. Therefore, the criteria for components deployment are taken by reading the BoP and rules for provisioning are implemented: when a given threshold (e.g. 20\% of the refill lot size) is achieved, an alert is run, and a vehicle transports the lot from the proper warehouse to the container. Moreover, the meta-model is able to deal with AGVs used in free navigation as well as on constrained paths.

The meta-model has been implemented in Flexsim, version 2017. Also in this case, a graphical interface has been implemented to support the user to quickly compile and deploy the model; it is shown in Fig. 1, right panel.

\section{Case study}

A case study taken from the automotive industry is shown in this section. The test process aims to assembly engine heads and is made of 19 operations belonging to 11 different technological families. All the machines to be used are assumed to have the same size, namely a length equal to $4 \mathrm{~m}$ and a width equal to $1.8 \mathrm{~m}$. Further, the minimum distance to be kept among cells is set to $5 \mathrm{~m}$, in order to enable material handling. The test room is a square with edge length equal to 50 meters. The plots in Fig. 2 show 


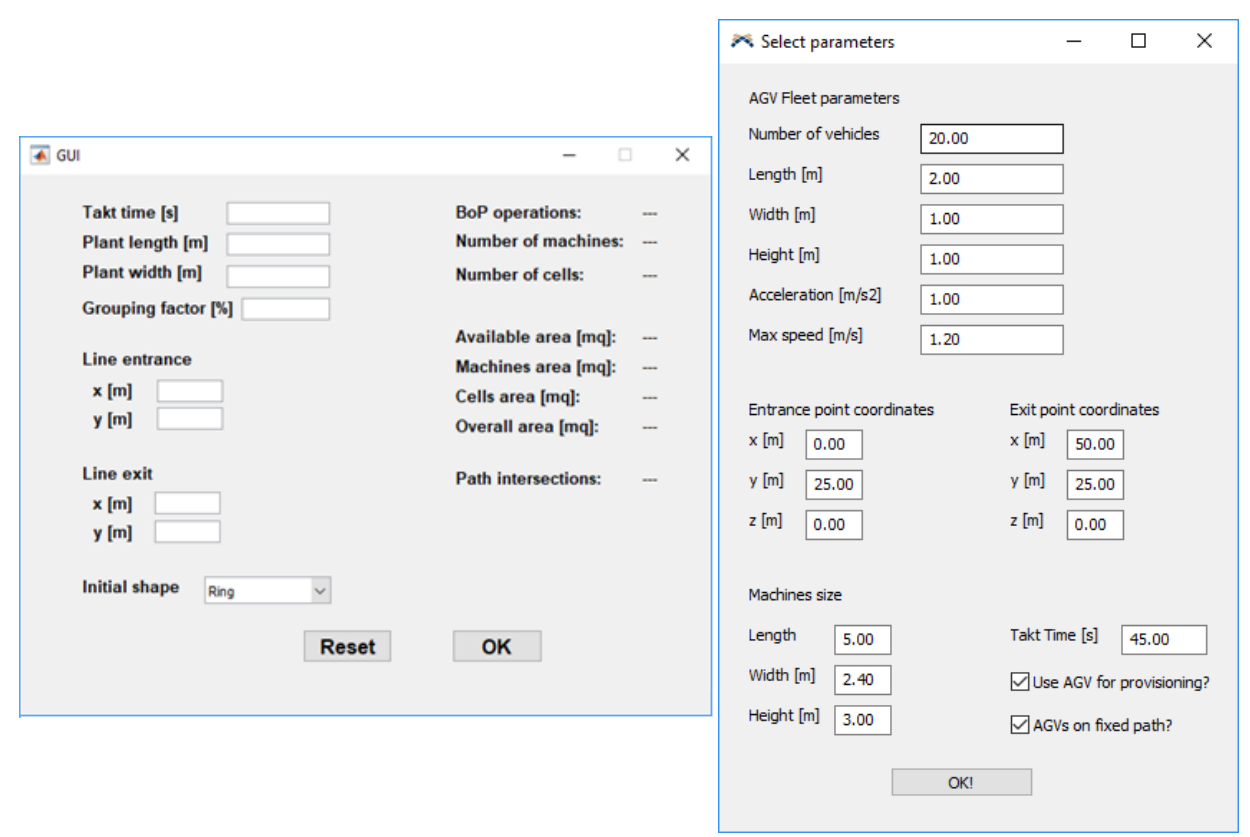

Fig. 1. Left. Graphical interface for the layout optimization tool. The input required by the user are collected on the left side; the performance indicators are shown on the right side.

Right. Graphical interface for the DES tool.

three alternative layout proposals obtained by varying the magnitude of the parameter Closeness. The entrance and exit points are on the left and right edges, respectively. As the value of Closeness increases, as expected, the number of machines decreases while the average distance travelled by each MU increases.

The layout proposal is then loaded into the discrete event simulation meta-model for the evaluation of dynamic scenarios: a screenshot of the model obtained for Closeness equal to 0.25 is shown in Fig. 3.

\section{Conclusions}

In the present paper, an integrated tool to support automated optimization and simulation of a hybrid product-process layout has been presented. This research is motivated by the availability - for a moderate price - of autonomous vehicles (such as the AGVs) capable to freely navigate throughout a given area. On the one side, the deployment of this technology enables to depict layouts with a reduced number of constraints; on the other side, a careful optimization must be made to achieve the best compromise between the quantity of machines to be used, the fleet of AGVs to be integrated, and the path to be travelled by each manufacturing unit. The latter factor, in turn, affects the work in process and the cycle time of the line, as well as possible safety issues due to traffic. An extended campaign to validate the mathematical model is discussed in [26]. It was found that by varying the grouping factor, the number of machines necessary to set a layout - and, in turn, the economic investment in manufacturing machines - may be reduced even by $50 \%$. In the same way, the average distance travelled by each MU arises, leading to a higher traffic level and an increased investment for the AGV fleet. 

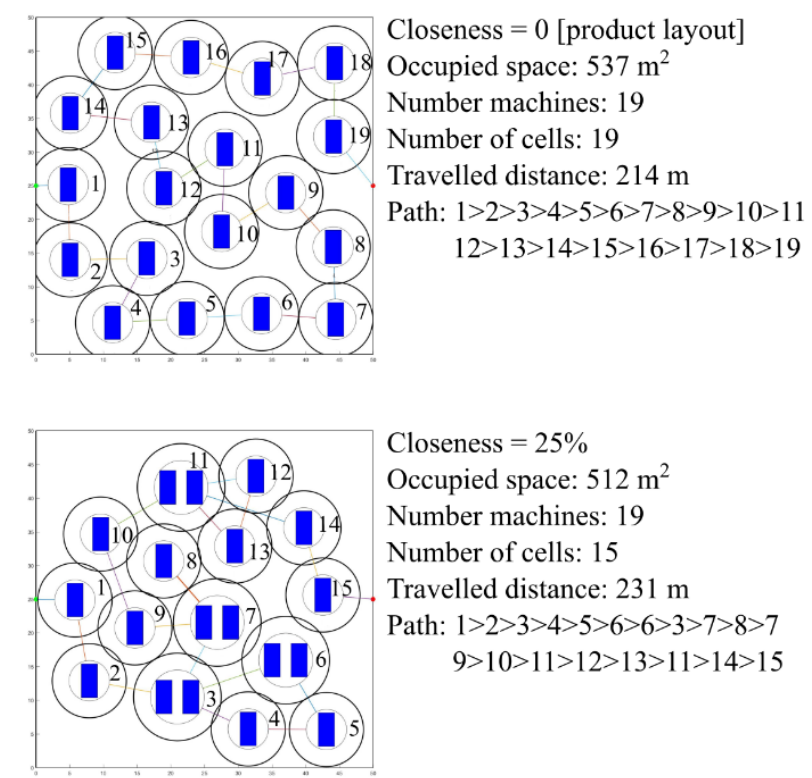

Closeness $=25 \%$

Occupied space: $512 \mathrm{~m}^{2}$

Number machines: 19

Number of cells: 15

Travelled distance: $231 \mathrm{~m}$

Path: $1>2>3>4>5>6>6>3>7>8>7$ $9>10>11>12>13>11>14>15$

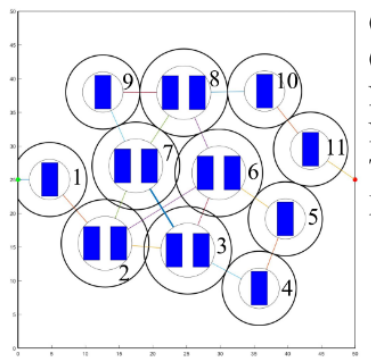

Closeness $=1$ [process layout $]$

Occupied space: $421 \mathrm{~m}^{2}$

Number machines: 16

Number of cells: 11

Travelled distance: $234 \mathrm{~m}$

Path: $1>2>3>4>5>6>6>3>7>3>7$

$2>6>8>9>7>8>10>11$

Fig. 2. Examples of layout obtained with the optimization tool. Blue rectangles represent the machines; the concentric circles represent the area occupied by the cell and the surrounding space to enable AGV transit.

The presented tool aims to support designers of manufacturing lines in performing their tasks. Tests performed on a common laptop (Intel i5 $2.6 \mathrm{GHz}$ CPU, 3 GB RAM) showed that the tool is able to evaluate a layout proposal in less than 10 seconds. The almost-real-time capability is maintained also by the simulation meta-model: given the input, the model is compiled within a few seconds. This result has two main implications: on the one hand, the routine activities are replaced by a tool that quickly evaluates the optimal machines positioning for a given input; on the other hand, different layouts for the same process can be generated and compared within a few minutes, enabling the designer to find the best trade-off between flexibility and economic investment. In further developments of the tool, the attention will be focused on the AGV fleet issues. At the current stage, the number of vehicles to be tested on the layout are input 


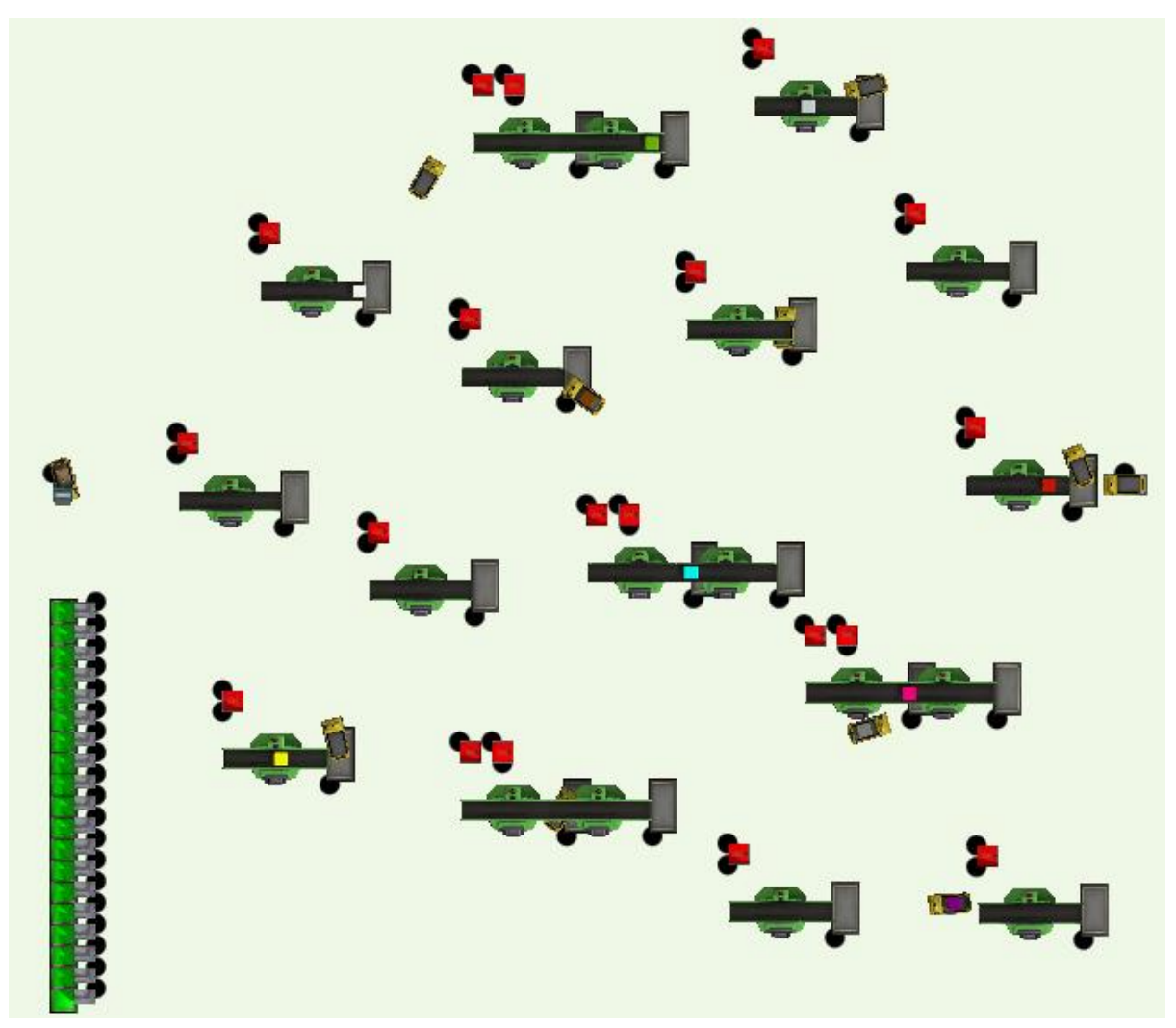

Fig. 3. Example of DES model obtained through the integrated tool. The green/black elements represent the workstations; the grey rectangles represent the bays for dropping off and picking up MUs. The yellow vehicles represent the AGVs, which interact with the production system through the black points. The red rectangles represent the containers of components close to the machines, while the warehouses are placed on left side of the layout.

by the designer; nonetheless, an automated estimation for the fleet size could be valuable. Further, energy concerns have not been considered; however, an estimation of the energy consumption and the downtimes for charging batteries should be included in the tool.

\section{Acknowledgements}

The research presented in this paper has been developed in partnership with COMAU S.p.A. and with Centro Ricerche Fiat. The research has been funded by Centro Ricerche Fiat within the project FlexAGV: Exploitation of flexibility in smart manufacturing systems, with the support of eng. J. Mascolo (CRF) and Andrea Ascheri (COMAU). 


\section{References}

1. Drira, A., Pierreval, H., Hajri-Gabouj, S.: Facility layout problems: a survey. Annual Reviews in Control 31(2), 255-267 (2007). http://dx.doi.org/10.1016/j.arcontrol.2007.04.001.

2. Tompkins, J., White, J., Bozer, Y., Tanchoco, J.: Facilities planning. Wiley (2010).

3. Heragu, S.S.: Facilities design. 4th edition. CRC Press (2016).

4. Armour, G.C., Buffa, E.S.: A heuristic algorithm and simulation approach to relative location of facilities. Management Science 9(2), 294-309 (1963). http://dx.doi.org/10.1287/mnsc.9.2.294.

5. Shayan, E., Chittilappilly, A.: Genetic algorithm for facilities layout problems based on slicing tree structure. International Journal of Production Research 42(19), 4055-4067 (2004). http://dx.doi.org/10.1080/00207540410001716471.

6. Anjos, M.F., Vieira, M.V.: Mathematical optimization approaches for facility layout problems: the state-of-the-art and future research directions. European Journal of Operational Research 261(1), 1-16 (2017). http://dx.doi.org/10.1016/j.ejor.2017.01.049.

7. Hassan, M.M.D.: Machine layout problem in modern manufacturing facilities. International Journal of Production Research 32(11), 2559-2584 (1994). http://dx.doi.org/10.1080/00207549408957084.

8. Kusiak, A., Heragu, S.S.: The facility layout problem. European Journal of Operational Research 29(3), 229-251 (1987). http://dx.doi.org/10.1016/0377-2217(87)90238-4.

9. Meller, R.D., Gau, K-Y. The facility layout problem: recent and emerging trends and perspectives. Journal of Manufacturing Systems 15(5), 351-366 (1996). http://dx.doi.org/10.1016/0278-6125(96)84198-7.

10. Singh, S.P., Sharma, R.R.K.: A review of different approaches to the facility layout problems. International Journal of Advanced Manufacturing Technology 30(5), 425-33 (2006). http://dx.doi.org/10.1007/s00170-005-0087-9.

11. Benjaafar, S., Sheikhzadeh, M.: Design of flexible plant layouts. IIE Transactions 32, 309322 (2000). http://dx.doi.org/10.1080/07408170008963909.

12. Meller, R.D., Kirkizoglu, Z., Chen, W.: A new optimization model to support a bottom-up approach to facility design. Computers \& Operational Research 37(1), $42-49$ (2010). http://dx.doi.org/10.1016/j.cor.2009.03.018.

13. Kouvelis, P., Kim, M.W.: Unidirectional loop network layout problem in automated manufacturing systems. Operational Research 40(3), 533-550 (1992). http://dx.doi.org/10.1287/opre.40.3.533.

14. Xie, W., Sahinidis, N.V.: A branch-and-bound algorithm for the continuous facility layout problem. Computers \& Chemical Engineering 32(4), 1016-1028 (2008). http://dx.doi.org/10.1016/j.compchemeng.2007.05.003.

15. Montreuil, B.: A modelling framework for integrating layout design and flow network design. In: Progress in Material Handling and Logistics, 95-115. Springer, Berlin (1991). http://dx.doi.org/10.1007/978-3-642-84356-3_8.

16. Meller, R.D., Narayanan, V., Vance, P.H.: Optimal facility layout design. Operational Research Letters 23(3), 117-127 (1998). http://dx.doi.org/10.1016/S0167-6377(98)00024-8.

17. Sherali, H.D., Fraticelli, B.M.P., Meller, R.D.: Enhanced model formulations for optimal facility layout. Operational Research 51(4), 629-644 (2003). http://dx.doi.org/10.1287/opre.51.4.629.16096.

18. Bukchin, Y., Tzur, M.: A new MILP approach for the facility process-layout design problem with rectangular and $\mathrm{L} / \mathrm{T}$ shape departments. International Journal of Production Research 52(24), 7339-7359 (2014). http://dx.doi.org/10.1080/00207543.2014.930534. 
19. Mak, K., Wong, Y., Chan, F.: A genetic algorithm for facility layout problems. Computer Integrated Manufacturing Systems 11(1), 113-127 (1998). http://dx.doi.org/10.1016/S09515240(98)00018-4.

20. Azadivar, F., Wang, J.: Facility layout optimization using simulation and genetic algorithms. International Journal of Production Research 38(17), 4369-4383 (2000). http://dx.doi.org/10.1080/00207540050205154.

21. Dunker, T., Radons, G., Westkämper, E.: A coevolutionary algorithm for a facility layout problem. International Journal of Production Research 41(15), 3479-3500 (2003). http://dx.doi.org/10.1080/0020754031000118125.

22. Galaxe-Paes, F., Alves-Pessoa, A., Vidal, T.: A hybrid genetic algorithm with decomposition phases for the unequal area facility layout problem. European Journal of Operational Research 256(3), 742-756 (2017). http://dx.doi.org/10.1016/j.ejor.2016.07.022.

23. Komarudin, K.Y.W.: Applying ant system for solving unequal area facility layout problems. European Journal of Operational Research 202(3), 730-746 (2010). http://dx.doi.org/10.1016/j.ejor.2009.06.016.

24. Niroomand, S., Hadi-Vencheh, A., Shahanaghi, R., Vizvári, B.: Modified migrating birds optimization algorithm for closed loop layout with exact distances in flexible manufacturing systems. Expert Systems and Applications 42(19), 6586-6597 (2015). http://dx.doi.org/10.1016/j.eswa.2015.04.040.

25. Sikaroudi, A.M.E, Shahanaghi, K.: Facility layout by collision detection and force exertion heuristics. Journal of Manufacturing Systems 41, 21-30 (2016). http://dx.doi.org/10.1016/j.jmsy.2016.07.001.

26. D'Antonio, G., Saja, A., Ascheri, A., Mascolo, J., Chiabert, P.: An integrated mathematical model for the optimization of hybrid product-process layouts. Journal of Manufacturing Systems 46, 179-192 (2018). https://doi.org/10.1016/j.jmsy.2017.12.003. 